\title{
Are NCAM deficient mice an animal model for schizophrenia?
}

\author{
Anne Albrecht ${ }^{1 *}$ and Oliver Stork ${ }^{1,2}$ \\ ${ }^{1}$ Department of Genetics and Molecular Neurobiology, Institute of Biology, Otto-von-Guericke University Magdeburg, Magdeburg, Germany \\ ${ }^{2}$ Center for Behavioral Brain Science, Magdeburg, Germany
}

\author{
Edited by: \\ Nuno Sousa, University of Minho, \\ Portugal \\ Reviewed by: \\ Juan Nacher, University of Valencia, \\ Spain \\ João M. Bessa, University of Minho \\ Braga, Portugal \\ *Correspondence: \\ Anne Albrecht, Department of \\ Genetics and Molecular \\ Neurobiology, Institute of Biology, \\ Otto-von-Guericke University \\ Magdeburg, Leipziger Str. 44, \\ 39120 Magdeburg, Germany. \\ e-mail: anne.albrecht@ovgu.de
}

Genetic and biomarker studies in patients have identified the Neural Cell Adhesion Molecule (NCAM) and its associated polysialic acid (PSA) as a susceptibility factors for schizophrenia. NCAM and polysialtransferase mutant mice have been generated that may serve as animal models for this disorder and allow to investigate underlying neurodevelopmental alterations. Indeed, various schizophrenia-relevant morphological, cognitive and emotional deficits have been observed in these mutants. Here we studied social interaction and attention of NCAM null mutant $\left(\mathrm{NCAM}^{-/-}\right)$mice as further hallmarks of schizophrenia. Nest building, which is generally associated with social behavior in rodents, was severely impaired, as $\mathrm{NCAM}^{-/-}$mice continuously collected smaller amounts of nest building material than their wild type littermates and built nests of poorer quality. However, social approach tested in a three-compartment-box was not affected and latent inhibition of Pavlovian fear memory was not disturbed in $\mathrm{NCAM}^{-/-}$mice. Although NCAM deficient mice do not display a typical schizophrenia-like phenotype, they may be useful for studying specific endophenotypes with relevance to the disease.

Keywords: NCAM, nest building, social interaction, latent inhibition, schizophrenia

\section{INTRODUCTION}

Genetic linkage and association studies suggest a polygenetic contribution of multiple risk genes that influence the susceptibility to develop schizophrenia (Gejman et al., 2011). Candidates comprise genes involved in synaptic plasticity, signal transduction, neurite outgrowth, and cell adhesion (Robertson et al., 2006). Single gene mutations are thought to contribute to less then $0.1 \%$ to the heritability of schizophrenia. Still, mice with genetic manipulations of identified susceptibility genes may provide valuable tools for better understanding the neurobiology of schizophrenia and the development of new therapeutic strategies. Testing of endophenotypes related to schizophrenia in animal models generally is focused on deficits in cognition, attention, and negative symptoms like emotional blunting or social dysfunction (Kellendonk et al., 2009; Mazzongini et al., 2009; Amann et al., 2010). The analysis of morphological changes in such rodent models has provided strong support for the neurodevelopmental hypothesis of schizophrenia (Robertson et al., 2006; Jaaro-Peled et al., 2010; Lu et al., 2011).

One molecule widely involved in neural development is the Neural Cell Adhesion Molecule (NCAM), which mediates $\mathrm{Ca}^{2+}$ independent cell-cell and cell-extracellular matrix interactions during proliferation, cell migration, neurite outgrowth, axon fasciculation, and synaptic remodeling (Fields and Itoh, 1996; Ronn et al., 2000; Povlsen and Ditlevsen, 2010). Altered concentrations of NCAM isoforms and soluble NCAM fragments have been frequently observed in the cerebrospinal fluid of schizophrenic patients (Vawter, 2000; Brennaman and Maness, 2010), as well as in hippocampus, prefrontal cortex (PFC) and other cortical areas (Vawter et al., 2001; Gibbons et al., 2009; Gray et al., 2010). Moreover, genetic association studies have identified NCAM as candidate susceptibility gene for schizophrenia, although findings were inconsistent (Vicente et al., 1997; Sullivan et al., 2007), raising the question whether NCAM may play a causal role in development of schizophrenia symptoms.

This may be addressed in mice with a targeted disruption of the NCAM gene $\left(\mathrm{NCAM}^{-/-}\right.$mice). These animals display moderate changes of brain morphology, reduced rhythmic network activity in the hippocampus, mild cognitive impairment and emotional changes including increased aggression, anxiety, and anti-depressant like responses (Cremer et al., 1994, 1997; Stork et al., 1997, 1999, 2000; Albrecht et al., 2010).

In this study we further investigated social behavior and attention deficits as core domains of schizophrenia, that previously could not be adequately assessed due to confounds from increased aggression (Stork et al., 1997) and memory deficits (Stork et al., 2000). Firstly, nest building behavior as a typical rodent behavioral feature linked to social activity (Crawley, 2007; Amann et al., 2010), and secondly social approach towards an unknown interaction partner in a three-chambered apparatus was assessed (Crawley, 2007), allowing to test for social behavior without interference by aggressive encounters in $\mathrm{NCAM}^{-/-}$mice. Recently, we could demonstrate that deficits in both auditory cued and contextual fear conditioning can be overcome by a pre-exposure of $\mathrm{NCAM}^{-/-}$mice to a neutral tone (CS-) and the training context (Albrecht et al., 2010). Engaging such pre-exposure strategies, we were now able to investigate attention processes in $\mathrm{NCAM}^{-/-}$ 
mice in a latent inhibition paradigm without adverse effects of fear memory deficits.

As $\mathrm{NCAM}^{-/-}$mice displayed disturbed nest building, but normal approach towards conspecifics as well as normal latent inhibition in the current study, we could not sustain the hypothesis that loss of NCAM is a critical factor for schizophrenia-like behavioral changes in general.

\section{MATERIALS AND METHODS}

NCAM mutants (backcrossed to C57Bl/6BomTac for > 12 generations) from heterozygous breeding were raised in groups of 2-6 under standard laboratory conditions with a $12 \mathrm{~h}$ day/night cycle (lights on at 7.00 P.M. with a $30 \mathrm{~min}$ dawn phase) and food and water ad libitum. Genotypes were determined by polymerase chain reaction as described previously (Stork et al., 2000). Mice were separated one week before the experiments and housed individually throughout the behavioral assessment. Testing of animals was always done during the dark cycle between 10.00 A.M. and 6.00 P.M. All experiments were in accordance with the European and German regulations and approved by the Landesverwaltungsamt Sachsonia-Anhalt AZ 2-441 and 2-618.

\section{SOCIAL BEHAVIOR \\ Nest building}

Male adult $\mathrm{NCAM}^{+/+}(N=14)$ and $\mathrm{NCAM}^{-/-}$mice $(N=18$; 10-16 weeks of age) were provided with a $2.2 \mathrm{~g}$ pellet of bedding cotton (Nestlets, $5 \times 5 \mathrm{~cm}$, EBECO, Castrop-Rauxel, Germany) accessible through the food hopper. The amount of cotton collected for nest building was determined over time. Nest quality was judged by a trained observer, who was blind for the animals' genotype, using a score system adapted from (Kalueff et al., 2006). ( 0 points $=$ no nest through 4 points $=$ hooded nest $)$. In the same manner, nest quality was rated after paper tissue was provided directly in the cage $\left(N=6\right.$ for $\mathrm{NCAM}^{-/-} ; N=7$ for $\mathrm{NCAM}^{+/+}$) to control for potential differences related to the nesting material or material gathering. Additionally, body temperature was determined both with nesting material in the cage and $24 \mathrm{~h}$ after nest removal. A small animal thermometer (TD-300; Shibaura Electric Co. Ltd., Tokyo, Japan) pre-warmed to $37^{\circ} \mathrm{C}$ in baby oil was introduced rectally. Measurements were always done between 12:00 and 13:00 and completed within $2 \mathrm{~min}$ to avoid stress-induced hypothermia.

\section{Social approach}

$\mathrm{NCAM}^{-/-}(N=8)$ and $\mathrm{NCAM}^{+/+}$mice $(N=10)$ were introduced into the center compartment of a $40 \times 60 \mathrm{~cm}$ threecompartment chamber. Transparent acryl plates with $6 \times 6 \mathrm{~cm}$ openings allowed free access to the neighbouring compartments each containing a perforated acrylic glass cylinder (diameter: $8 \mathrm{~cm}$ ) for housing an interaction partner. After $5 \mathrm{~min}$ of free exploration test mice were confined to the center compartment for $1 \mathrm{~min}$ while an unfamiliar male wild type mouse serving as interaction partner was placed in one of the cylinders while the cylinder in the other compartment remained empty. The test mouse was allowed to explore all compartments for 30 min during which movements were video recorded and tracked with ANY-maze (Stoelting, Wood Dale, IL, USA). An observer blind for genotype of the test mouse and location of the interaction partner scored direct contacts with key presses.

\section{LATENT INHIBITION}

To generate latent inhibition, $\mathrm{NCAM}^{-/-}$mice $(N=12)$ and their $\mathrm{NCAM}^{+/+}$littermates $(N=12)$ were pre-exposed to 40 $\mathrm{CS}+$ tones $(10 \mathrm{kHz}, 85 \mathrm{~dB} \mathrm{SPL})$, which were presented in four sessions of each 10 over two days. In each session, after 2 min of habituation, ten $10 \mathrm{~s}$ stimuli were presented with inter-stimulusintervals (ISI) of $20 \mathrm{~s}$ (CS+ PE group). A second group of $\mathrm{NCAM}^{-/-}(N=12)$ and $\mathrm{NCAM}^{+/+}$mice $(N=12)$ received pre-exposure to 40 neutral acoustic stimuli of $2.5 \mathrm{kHz}$ (CS- PE group) and a third group of $\mathrm{NCAM}^{-/-}(\mathrm{N}=12)$ and $\mathrm{NCAM}^{+/+}$ mice $(N=12)$ was pre-exposed only to the training context, but no tone (Cxt PE). In all groups, fear conditioning on day three was done by pairing three CS+ $(9 \mathrm{~s}, 10 \mathrm{kHz}, 85 \mathrm{~dB})$ with mild electric foot shocks ( $1 \mathrm{~s}, 0.4 \mathrm{~mA}$; ISI $20 \mathrm{~s}$ ). Fear memory retrieval was tested $24 \mathrm{~h}$ later in a neutral context. After $2 \mathrm{~min}$ sets of each four CS- and four CS + with 20 s ISI were presented for auditory cued fear memory. On the next day, memory to the training context was tested for $2 \mathrm{~min}$. Freezing behavior as a measure of fear memory was determined with a photo beam detection according to previously established parameters (Laxmi et al., 2003; Albrecht et al., 2010).

\section{RESULTS SOCIAL BEHAVIOR \\ Nest building}

The analysis of cotton sampling activity showed a significant effect of genotype on the amount of nesting material used [ANOVA with effect of gene $F_{(1,30)}=35.887 ; p<0.001$ ]. Over time, animals of both genotypes collected more nest material [repeated measurement ANOVA with time as factor: time $\left.F_{(5,150)}=31.895, p<0.001\right]$, but a genotype effect was observed over time [time $\times$ genotype interaction $F_{(5,150)}=9.928$, $p<0.001$ ]. In fact even after $48 \mathrm{~h} \mathrm{NCAM}^{-/-}$mice had used only $32 \pm 8.8 \%$ (mean $\pm \mathrm{SEM}$ ), while their $\mathrm{NCAM}^{+/+}$littermates had taken $80 \pm 9.3 \%$ of the provided cotton (Figure 1A).

Moreover, $\mathrm{NCAM}^{-/-}$mice built only primitive nests, while $\mathrm{NCAM}^{+/+}$animals managed to form more complex, cup-shaped nests with the collected cotton [ANOVA for effect of gene: $\left.F_{(1,30)}=36.872 ; p<0.001\right]$. It took all animals several hours to construct their nests [repeated measurement ANOVA with time as factor: time $\left.F_{(5,150)}=25.552 ; p<0.001\right]$, but the genotype effect was stable over time [time $\times$ genotype: $F_{(5,150)}=5.004$, $p<0.001 ;$ Figure 1B].

Similarly, when the nesting material was provided directly in the cage, $\mathrm{NCAM}^{-/-}$animals built nests of poor quality, revealing a significant effect of the genotype [ANOVA for effect of gene: $F_{(1,12)}=53.269 ; p<0.001$; Figure 1C].

Since an altered function of the serotonergic system has been described in NCAM mutant mice (Stork et al., 2000) that might affect nesting behavior by altering thermoregulation, we measured the body temperature in the presence of the nest $(\mathrm{t} 0)$ and $24 \mathrm{~h}$ after its removal (t 24). No significant difference between 


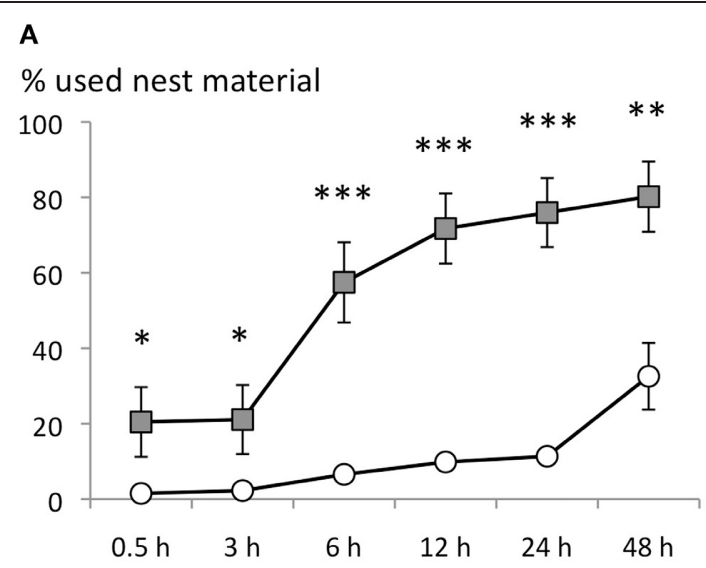

C

Nest quality score

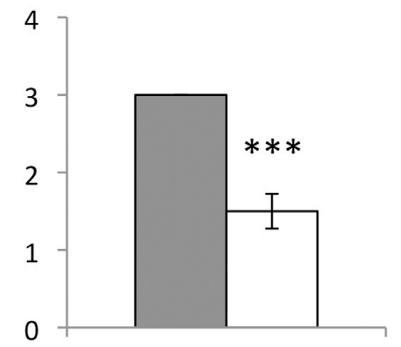

1 week

E

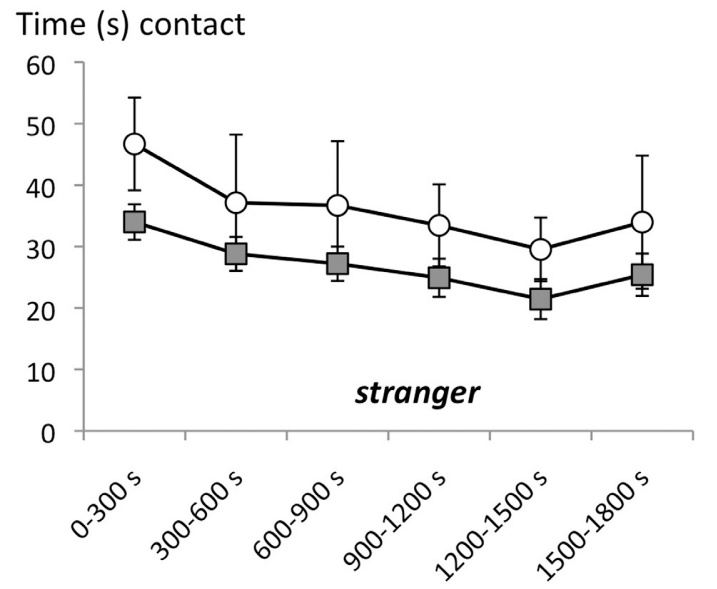

FIGURE 1 | Disturbed nest building, but normal social approach in $\mathbf{N C A M}^{-/-}$mice. (A) $\mathrm{NCAM}^{-/-}$mice collected continuously less amounts of cotton tissue from the food hopper than their wild type littermates.

(B) Consistently, $\mathrm{NCAM}^{-/-}$mice built only primitive flat nests. (C) Similar, when tissue paper was provided as nesting material in the cage $\mathrm{NCAM}^{-1-}$ mice built only nests of poor quality, as assessed after one week. (D) The body temperature of $\mathrm{NCAM}^{-/-}$mice did not differ significantly from
B

Nest quality score

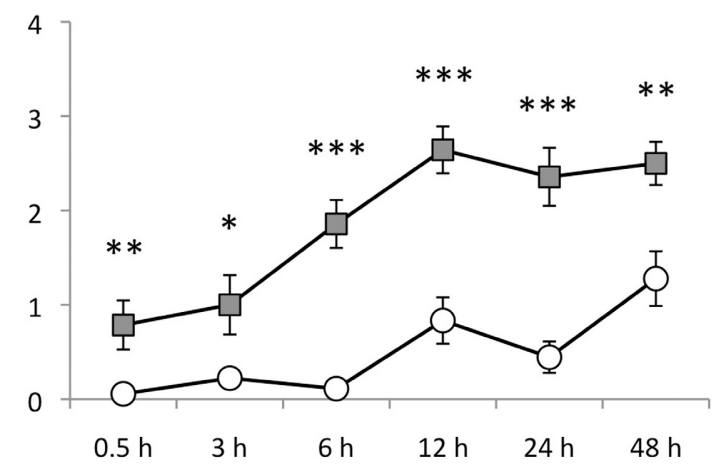

D

Body temperature $\left({ }^{\circ} \mathrm{C}\right)$

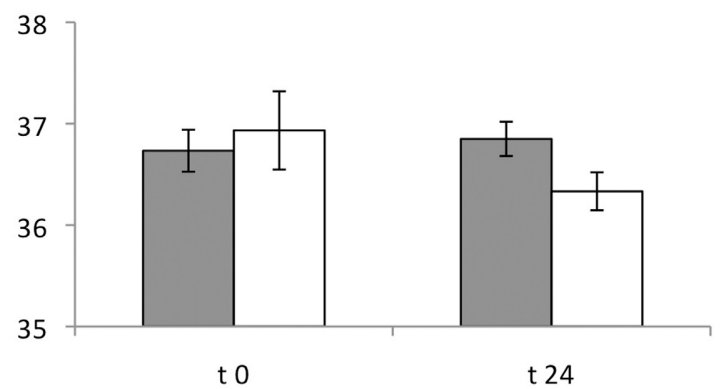

t 0

t 24

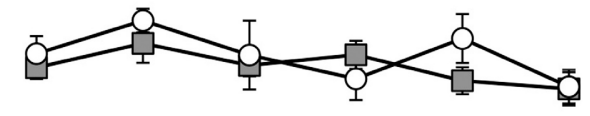

empty

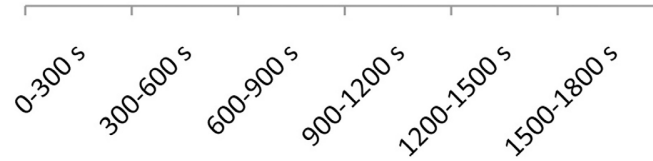

$\mathrm{NCAM}^{+/+}$mice either with a nest available at $\mathrm{t} 0$ or $24 \mathrm{~h}$ after removal of the nesting material at $t 24$. (E) In a social interaction test $\mathrm{NCAM}^{-/-}$mice displayed no deficits in direct approaches towards a tube containing the stranger mouse (left column) and showed comparable amounts of contacts towards an empty tube compared to $\mathrm{NCAM}^{+/+}$mice. Values are indicated as mean \pm SEM. * Significant difference between genotypes with $p<0.05$; ${ }^{* *} p<0.01 ;{ }^{* * *} p<0.001$. genotypes could be observed [ANOVA for effect of gene at t $0: F_{(1,10)}=0.209 ; p=0.675$; at $\mathrm{t} 24: F_{(1,10)}=4.197 ; p=$ 0.068 ], suggesting a normal thermoregulatory control in NCAM mutant mice (Figure 1D).

\section{Social approach}

Over the $30 \mathrm{~min}$ test period, repeated measures ANOVA with 5 min segments as repeated factor and genotype as inter-subject factor revealed no difference between genotypes for the time 
spent either in the compartment with the stranger mouse $\left[F_{(1,16)}=1.381 ; p=0.257\right]$ or for time spent in the empty compartment $\left[F_{(1,16)}=2.035 ; p=0.173\right]$. Mice of both genotypes spent more time in direct contact with the tube containing the stranger mouse, with contact time decreasing over the test period [segment: $F_{(5,80)}=3.662 ; p=0.005$; genotype: $\left.F_{(1,16)}=1.666 ; p=0.215\right]$. Time spent in direct contact with an empty tube also decreased over the test segments $\left[F_{(5,80)}=2.756 ; p=0.024\right]$, but again no difference between genotypes was detected $\left[F_{(1,16)}=0.461 ; p=0.507\right.$; Figure 1E $]$.

Together, $\mathrm{NCAM}^{-/-}$mice showed social affiliation behavior towards a stranger mouse comparable to their wild type littermates, although nest building was disturbed in the mutant mice.

\section{LATENT INHIBITION}

Latent inhibition of auditory cued fear memory was achieved in $\mathrm{NCAM}^{-/-}$and $\mathrm{NCAM}^{+/+}$mice by pre-exposure to the conditioned tone before training $(\mathrm{CS}+\mathrm{PE})$, and compared to control groups that received pre-exposure to the context (Cxt PE) or a neutral tone (CS - PE).

Freezing to the CS+ during the retrieval was affected by genotype and pre-exposure [Two-Way-ANOVA for genotype: $F_{(1,65)}=5.829 ; p=0.019$; for group: $F_{(2,65)}=15.295$; $p=0.000$; genotype $\mathrm{x}$ group interaction: $F_{(2,65)}=2.946$; $p=0.06]$. Mice of both genotypes showed comparably low levels of freezing to the CS+ after CS+ pre-exposure (mean \pm SEM: $12.99 \pm 3.53$ for $\mathrm{NCAM}^{+/+}$and $15.42 \pm 2.84$ for $\mathrm{NCAM}^{-/-}$ mice). Targeted comparison of pre-exposure group effects in each genotype demonstrated successful latent inhibition in $\mathrm{NCAM}^{+/+}$ mice with significantly higher levels of freezing after context preexposure (mean \pm SEM: $37.71 \pm 4.52 ; p=0.000$ to $\mathrm{CS}+\mathrm{PE}$ ) and CS- pre-exposure (mean \pm SEM: $39.93 \pm 3.73 ; p=0.000$ to $\mathrm{CS}+\mathrm{PE}$ ). In $\mathrm{NCAM}^{-/-}$mice freezing to the $\mathrm{CS}+$ was also significantly increased after CS- pre-exposure (mean \pm SEM:
$30.76 \pm 3.77 ; p=0.009$ to $\mathrm{CS}+\mathrm{PE})$. However, after context preexposure, freezing to the CS+ was reduced in $\mathrm{NCAM}^{-/-}$mice (mean \pm SEM: $20.98 \pm 5.20$; n.s. to CS + PE) compared to their wild type littermates ( $p=0.024$; Figure 2A).

Freezing to the context, in which the training occurred, was not affected by the different pre-exposure paradigms [Two-WayANOVA; effect of group: $F_{(2,65)}=1.252 ; p=0.293$ ]. However, ANOVA revealed an effect of genotype $\left[F_{(1,65)}=7.242 ; p=\right.$ $0.009]$ and a genotype $\times$ group interaction $\left[F_{(2,65)}=3.336\right.$, $p=0.042]$ on freezing towards the conditioned context. While $\mathrm{NCAM}^{+/+}$mice showed comparable amounts of freezing in each pre-exposure group (mean \pm SEM: $44.44 \pm 7.16$ for context pre-exposure; mean \pm SEM: $56.60 \pm 6.87$ for CS- preexposure; mean \pm SEM: $51.67 \pm 7.08$ for CS + pre-exposure), they displayed reduced freezing to the context when pre-exposed to the CS- (mean \pm SEM: $21.11 \pm 3.69$ for CS- pre-exposure vs. $47.01 \pm 8.89$ for $\mathrm{CS}+$ pre-exposure; $p=0.009 ; p=0.000$ $\mathrm{NCAM}^{+/+}$vs. $\mathrm{NCAM}^{-/-}$in CS+ pre-exposure; Figure 2B).

Together, these results demonstrate that in $\mathrm{NCAM}^{-/-}$mice normal latent inhibition of auditory cued fear memory is possible, in spite of specific memory deficits to both CS+ and the training context.

\section{DISCUSSION}

In the current study we tested the hypothesis that previously observed neurodevelopmental, cognitive and emotional deficits in $\mathrm{NCAM}^{-/-}$mice may be part of a complex phenotype of schizophrenic-like behavior. To this end, we further analyzed social interaction and attention that previously could not be adequately assessed due to confounds from increased aggression (Stork et al., 1997) and memory deficits (Stork et al., 2000). Our results reveal disturbed nest building, but normal approach towards conspecifics in $\mathrm{NCAM}^{-/-}$mice, as well as normal latent inhibition compared to wild types and to mutants with attenuated memory deficits. Hence although several behavioral domains

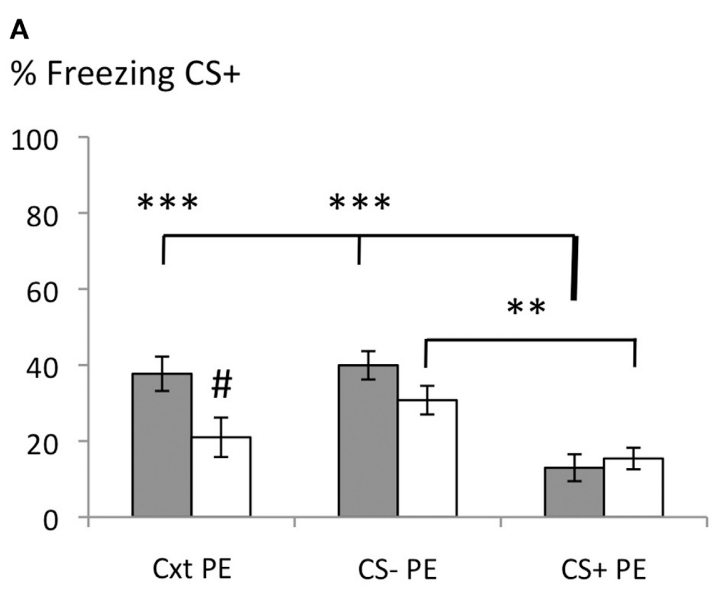

FIGURE 2 | No deficits of latent inhibition in $\mathrm{NCAM}^{-/-}$mice.

(A) Freezing response to the conditioned stimulus $(\mathrm{CS}+)$ was reduced in both genotypes when pre-exposure to the CS+ was conducted (CS + PE). $\mathrm{NCAM}^{-/-}$mice show reduced freezing when pre-exposure occurred only to the training context (Cxt PE). (B) Freezing response to the context was
B

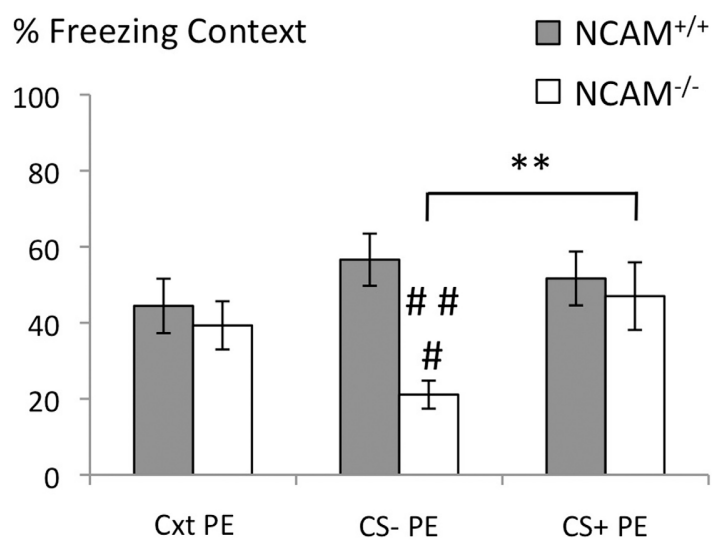

reduced in NCAM deficient mice when pre-exposed to the CSonly (CS-PE). Values are indicated as mean \pm SEM. ${ }^{* *}$ Significant difference between pre-exposure procedures, $p<0.01$.

*** $p<0.001$. "Significant difference between genotypes, $p<0.05$; \#\#\#, $p<0.001$. 
affected in schizophrenia are sensitive to NCAM mutation, the overall phenotypic profile of $\mathrm{NCAM}^{-/-}$mice does not fully resemble a schizophrenic-like pattern.

A genetic mouse model cannot be expected to reproduce all aspects of schizophrenia, especially considering the variability among schizophrenia patients and similarities to other disorders. For example, impaired social interaction is also a core feature of autism spectrum disorders and there exists an overlap between autistic and, especially, negative symptoms of schizophrenia (e.g., affective flattening, social impairments, and poor communication) as well as a shared difficulty to adapt to novel and stressful situations (see Tordjman et al., 2007 for review). In fact, several well established models display morphological and behavioral alterations in some, but not all domains (e.g., disrupted in schizophrenia-1 (DISC-1), neuregulin-1 (NRG-1), NMDA receptor subunit 1 (NR1) or catechol-o-methyltransferase (COMT); (for review, see: Gainetdinov et al., 2001; O'Tuathaigh et al., 2007; Kellendonk et al., 2009; Jaaro-Peled et al., 2010; Lu et al., 2011). Nevertheless, some of the behavioral and morphological phenotypes associated with schizophrenia have been observed in
$\mathrm{NCAM}^{-/-}$mice (see Table 1 for overview). These include morphological alterations like a reduced olfactory bulb size (Cremer et al., 1994; Stork et al., 2000) and disturbed mossy fiber architecture (Cremer et al., 1997), which have likewise been reported in schizophrenic patients (Turetsky et al., 2000; Kolomeets et al., 2007; Tamminga et al., 2010). Alterations in neural connectivity are also related to changes in oscillatory activity in the theta and gamma frequency range that are frequently observed in schizophrenic patients (Uhlhaas et al., 2008; Lisman, 2011). In $\mathrm{NCAM}^{-/-}$mice, a reduced amygdalo-hippocampal theta synchronization is observed during fear memory retrieval (Albrecht et al., 2010).

$\mathrm{NCAM}^{-/-}$mice also display some behavioral changes potentially related to schizophrenia, e.g., hyperactivity and impaired spatial learning (Cremer et al., 1994; Stork et al., 2000). Interestingly, cognitive deficits in contextual fear conditioning were augmented in $\mathrm{NCAM}^{-/-}$mice using more stressful paradigms (Albrecht et al., 2010). In conditional NCAM deficient mice with a forebrain-specific postnatal reduction of NCAM expression disturbed cognitive functions are also evident in fear

Table 1 | Phenotypes of NCAM $^{-/-}$mice relevant to schizophrenia.

\begin{tabular}{|c|c|c|c|}
\hline Functional domain & Factor tested & Findings in $\mathrm{NCAM}^{-/-}$mice & Reference \\
\hline & $\begin{array}{l}\text { Olfactory bulb } \\
\text { Hippocampus }\end{array}$ & $\begin{array}{l}\text { reduced size, disturbed migration } \\
\text { from } S V Z\end{array}$ & $\begin{array}{l}\text { Cremer et al., 1994; Stork et al., } \\
2000\end{array}$ \\
\hline & & $\begin{array}{l}\text { disturbed mossy fiber } \\
\text { architecture }\end{array}$ & Cremer et al., 1994, 1997 \\
\hline \multicolumn{4}{|l|}{ ELECTROPHYSIOLOGY } \\
\hline \multicolumn{4}{|l|}{ BEHAVIOR } \\
\hline Locomotion & Open field activity & $\uparrow$ & Stork et al., 2000 \\
\hline Sensory gating & PPI & $=$ & Plappert et al., 2005 \\
\hline Attention & Latent inhibition & $=$ & Figure 2 \\
\hline \multirow[t]{2}{*}{ Cognitive functions } & Morris Water Maze & $\begin{array}{l}\downarrow \\
\downarrow^{*} \\
\downarrow \downarrow \text { by stress* }\end{array}$ & $\begin{array}{l}\text { Cremer et al., 1994; Bisaz et al., } \\
\text { 2011; Bisaz and Sandi, } 2012\end{array}$ \\
\hline & Cued fear conditioning & $\begin{array}{l}\downarrow /= \\
\downarrow^{*}\end{array}$ & $\begin{array}{l}\text { Albrecht et al., 2010; Stork et al., } \\
\text { 2000; Bisaz and Sandi, } 2010\end{array}$ \\
\hline \multirow[t]{2}{*}{ Social interaction } & Nest building & $\downarrow$ & Figures $1 A-D$ \\
\hline & 3-compartment test & $=$ & Figure 1E \\
\hline \multicolumn{4}{|c|}{ NEUROTRANSMITTER SIGNALING } \\
\hline \multirow[t]{2}{*}{ Serotonergic signaling } & $5 \mathrm{HT} 1 \mathrm{~A}$ receptor expression & $=$ & Stork et al., 1999 \\
\hline & $\begin{array}{l}\text { Sensitivity to serotonergic } \\
\text { compounds }\end{array}$ & $\uparrow$ & Stork et al., 2000 \\
\hline \multirow[t]{2}{*}{ Dopaminergic signaling } & D2 receptor expression & $\uparrow$ & Xiao et al., 2009 \\
\hline & $\begin{array}{l}\text { Sensitivity to dopaminergic } \\
\text { compounds }\end{array}$ & $\uparrow$ & Xiao et al., 2009 \\
\hline
\end{tabular}

Comparison of morphological (Turetsky et al., 2000; Kolomeets et al., 2007; Tamminga et al., 2010) and electrophysiological alterations (Uhlhaas et al., 2008; Lisman, 2011) found in schizophrenic patients as well as behavioral assays relevant for schizophrenia- associated symptoms (Mazzongini et al., 2009; Amann et al., 2010) and altered neurotransmitter signaling (Joober et al., 2002) with alterations in NCAM-1- mice described previously and in this study. *Indicates findings from conditional, forebrain-specific NCAM deficient mice. Some cognitive deficits in constitutive and conditional NCAM-1- mice can be further enhanced by stress. 
conditioning as well as spatial and reversal learning in the Morris water maze (Bisaz and Sandi, 2010; Bisaz et al., 2011). This suggests that disturbance of acute NCAM-mediated cell recognition events rather than developmental effects of NCAM deficiency may cause these cognitive impairments. Moreover, subchronic stress further enhances deficits in water maze reversal learning in the conditional NCAM deficient mice but has no effect on their wildtype littermates (Bisaz and Sandi, 2012), suggesting that reduced NCAM expression may serve as a vulnerability factor for expression of behavioral impairments after stressful experience. This is in line with observations in schizophrenia, where psychosocial stress can trigger the initial expression or exacerbation of symptoms (Walker et al., 2008).

However, the changes reported so far are not disease-specific and alterations in behavioral domains not directly relevant for schizophrenia could compromise the analysis in these animals. In the current study we employed paradigms in which confounding conditions are minimized to analyze two core symptoms of schizophrenia, loss of sociability and attention deficits.

Considering that $\mathrm{NCAM}^{-/-}$mice show increased aggressive behavior in an intruder aggression paradigm, we engaged nonconfrontative paradigms to test social behavior without aggressive encounters. Firstly, we assessed nest building behavior as a typical rodent behavioral feature linked to social activity (Crawley, 2007; Amann et al., 2010). Nest building behavior is a speciesspecific innate behavioral response important for thermoregulatory control and critical for the fitness of wild and laboratory mice (DeLuca et al., 1989; Bult and Lynch, 1997). However, we observed in $\mathrm{NCAM}^{-/-}$mice a severe quantitative and qualitative disturbance of nest building that was independent of any change in body temperature or response to novelty. Nest building is disturbed in various mutants with social interaction deficits (Moretti et al., 2005; Crawley, 2007; Samaco et al., 2008; Etherton et al., 2009) and also observed in other mouse models for schizophrenia (Belforte et al., 2010). Therefore secondly, we analyzed social approach towards an unknown interaction partner in a three-chambered apparatus, which allows for sensory contact but prevents aggressive encounters (Crawley, 2007). Under these conditions, a non-significant trend of $\mathrm{NCAM}^{-/-}$ mice to increasingly approach the unfamiliar interaction partner was detectable. Since olfactory deficits in $\mathrm{NCAM}^{-/-}$mice (Cremer et al., 1994) have been described, we employed an additional social interaction apparatus that allows tactile interaction between test and stranger mouse (i.e., a smaller compartment containing the interaction partner is divided from a larger compartment containing the test animal by a wire mesh fence). Again, $\mathrm{NCAM}^{-/-}$mice displayed comparable levels of interaction to their wild type littermates (data not shown), thus supporting our finding of undisturbed social approach in a neutral test setting, in spite of reported aggression, hyperactivity and olfactory deficits (Cremer et al., 1994; Stork et al., 2000).

Disturbance of attentive stimulus processing is another hallmark of schizophrenia with patients giving and maintaining increased attention to irrelevant stimuli (Weiner, 2003; Lubow, 2005). In rodents, attention deficits can be uncovered in a latent inhibition paradigm, in which repeated stimulus preexposure attenuates its association with an unconditioned stimulus (Weiner, 2003). Since $\mathrm{NCAM}^{-/-}$mice display deficits in both auditory cued and contextual fear conditioning (Stork et al., 2000), investigation of latent inhibition in these paradigms could be compromised. However, we could show recently that these deficits can be overcome by a pre-exposure of $\mathrm{NCAM}^{-/-}$mice to a neutral tone (CS-) and the training context (Albrecht et al., 2010). This now allowed us to investigate latent inhibition without confounds through fear memory deficits. Pre-exposure to the CS- as well as to the CS+ resulted in comparable freezing levels between $\mathrm{NCAM}^{-/-}$and $\mathrm{NCAM}^{+/+}$mice. Animals of both genotypes reduced freezing towards the $\mathrm{CS}+$ after $\mathrm{CS}+$ preexposure, hence failing to provide evidence for attention deficits in $\mathrm{NCAM}^{-/-}$mice.

Thus, morphological and behavioral data demonstrate that $\mathrm{NCAM}^{-/-}$mice show only deficits in a subset of behavioral domains associated with schizophrenia, while other changes cannot be linked to this disease. Considering different aspects of NCAM function, its regulation through post-translational modifications and its various interaction partners may shed some light on this puzzle.

The extracellular portion of the NCAM molecule (NCAM-EC) can be cleaved by metalloproteases, which results in inhibition of neurite outgrowth and arborization of cortical neurons during development (Brennaman and Maness, 2008). Increased concentrations of NCAM-EC have been also observed in the cerebrospinal fluid of schizophrenic patients (Vawter et al., 2001). Based on this, Pillai-Nair et al. (2005) developed transgenic mice that secrete an extracellular NCAM fragment. These animals display cytomorphological changes in the PFC as well as schizophrenia-related behavioral changes, including hyperactivity, working memory deficits and clozapine-reversible disturbance of prepulse inhibition (PPI). Strikingly, PPI, a pre-attentive sensory gating process, was found unaltered in $\mathrm{NCAM}^{-/-}$mice (Plappert et al., 2005). Thus, mechanisms that control NCAMmediated cell adhesion through protein expression and shedding appear to differentially affect certain schizophrenia-related phenotypes.

NCAM-mediated adhesion and its functions during development and in certain regions of the mature brain are highly dependent on its posttranslational modification by polysialic acid (PSA). PSA is added to the NCAM core protein through two Golgi-associated polysialyltransferases, ST8SiaII and ST8SiaIV, in a strictly regulated pattern (Bonfanti, 2006). And indeed, single nucleotide polymorphisms in the promoter region of the polysialyltransferases ST8SiaII have been also linked to schizophrenia (Arai et al., 2006; Tao et al., 2007). PSA has been implicated in the NCAM-mediated morphogenic processes in the olfactory bulb and hippocampal mossy fiber system (Hu et al., 1996; Seki and Rutishauser, 1998) as well as the interplay of stress and synaptic plasticity (Bisaz et al., 2009). ST8SiaIV mutant mice showed deficits in hippocampal plasticity (Eckhardt et al., 2000) and spatial memory (Markram et al., 2007), resembling deficits in $\mathrm{NCAM}^{-/-}$mice (Cremer et al., 1994; Stork et al., 2000). This similarity of phenotypes suggests that polysialylated NCAM may be its relevant form in these mnemonic processes. 
Interestingly, PSA is able to bind dopamine and a mutated form of ST8SiaII that has been observed also in schizophrenic patients previously, produces a PSA-NCAM type were this function is lost (Isomura et al., 2011). On the other hand, D2 receptor internalization is reduced and D2 surface expression and signaling are increased in $\mathrm{NCAM}^{-/-}$mice (Xiao et al., 2009). Castillo-Gómez et al. (2008) previously found reduced expression of PSA-NCAM after chronic treatment with haloperidol, an antipsychotic drug acting as a dopamine receptor type 2 (D2) antagonist, and an corresponding increase following a D2 agonist 2-(N-Phenethyl-N-propyl) amino-5-hydroxytetralin hydrochloride, In contrast, no D2-dependent expression modulation of the NCAM core protein is observed when PSA is enzymatically removed (Castillo-Gómez et al., 2011). Together these data indicate a differential interaction of the NCAM core protein and NCAM-PSA in the interaction with dopamine receptors, which appears to be negatively correlated with the strength of NCAMmediated adhesion.

In addition, expression of PSA-NCAM in the PFC is modulated by serotonergic transmission (Varea et al., 2007). We have previously seen that without detectable changes in serotonin levels and 5-HT1A receptor expression, $\mathrm{NCAM}^{-/-}$mice display increased responsiveness to serotonergic anxiolytics (Stork et al., 1999, 2000). This serotonergic hypersensitivity may relate to an interaction of NCAM with inwardly rectifying potassium channels (Kir3.1, Delling et al., 2002), which itself has recently been

\section{REFERENCES}

Albrecht, A., Bergado-Acosta, J. R., Pape, H. C., and Stork, O. (2010). Role of the neural cell adhesion molecule (NCAM) in amygdalo-hippocampal interactions and salience determination of contextual fear memory. Int. J. Neuropsychopharmacol. 13, 661-674.

Amann, L. C., Gandal, M. J., Halene, T. B., Ehrlichman, R. S., White, S. L., McCarren, H. S., and Siegel, S. J. (2010). Mouse behavioral endophenotypes for schizophrenia. Brain Res. Bull. 83, 147-161.

Arai, M., Yamada, K., Toyota, T., Obata, N., Haga, S., Yoshida, Y., Nakamura, K., Minabe, Y., Ujike, H., Sora, I., Ikeda, K., Mori, N., Yoshikawa, T., and Itokawa, M. (2006). Association between polymorphisms in the promoter region of the sialyltransferase $8 \mathrm{~B}$ (SIAT8B) gene and schizophrenia. Biol. Psychiatry 59, 652-659.

Belforte, J. E., Zsiros, V., Sklar, E. R., Jiang, Z., Yu, G., Li, Y., Quinlan, E. M., and Nakazawa, K. (2010). Postnatal NMDA receptor ablation in corticolimbic interneurons confers schizophrenia-like phenotypes. Nat. Neurosci. 13, 76-83.

Bisaz, R., Conboy, L., and Sandi, C. (2009). Learning under stress: a role for the neural cell adhesion molecule NCAM. Neurobiol. Learn. Mem. 91, 333-342.

Bisaz, R., Schachner, M., and Sandi, C. (2011). Causal evidence for the involvement of the neural cell adhesion molecule, NCAM, in chronic stress-induced cognitive impairments. Hippocampus 21, 56-71.

Bisaz, R., and Sandi, C. (2010). The role of NCAM in auditory fear conditioning and ist modulation by stress: a focus on the amygdala. Genes Brain Behav. 9, 353-364.

Bisaz, R., and Sandi, C. (2012). Vulnerability of conditional NCAM-deficient mice to develop stress-induced behavioral alterations. Stress 15, 195-206.

Bonfanti, L. (2006). PSA-NCAM in mammalian structural plasticity and neurogenesis. Prog. Neurobiol. 80, 129-164.

Brennaman, L. H., and Maness, P. F. (2008). Developmental regulation of GABAergic interneuron branching and synaptic development in the prefrontal cortex by soluble neural cell adhesion molecule. Mol. Cell. Neurosci. 37, 781-793.

Brennaman, L. H., and Maness, P. F. (2010). NCAM in neuropsychiatric and neurodegenerative disorders. Adv. Exp. Med. Biol. 663, 299-317.

identified as a schizophrenia susceptibility gene (Yamada et al., 2012). However, the potential role of PSA in these processes is not yet clear.

The compiled evidence from genetic association studies and mutant mouse analysis suggests that the NCAM associated-cell recognition and signaling complex (including FGF receptors: Terwisscha van Scheltinga et al., 2010; and NMDA receptors: Kochlamazashvili et al., 2010) are involved in the development of schizophrenia-related behavioral features. A systematic functional analysis of the different components of this complex and their interaction in nervous system development will help us to better understand the underlying pathophysiology. First steps have been taken by crossbreeding knock out strains for NCAM, ST8SiaII and ST8SiaIV, which revealed that imbalanced polysialylation of NCAM during development causes morphological deficits similar to those in schizophrenic patients (Hildebrandt et al., 2009). The fine differential sensitivity of cognitive functions, neuromodulation and social behavior and to mutations in the NCAM cell recognition complex will certainly help to further dissect these processes.

\section{ACKNOWLEDGMENTS}

We are grateful to Franziska Webers for excellent technical assistance and to Angela Deter and Theresa Nawrath for animal care. We further thank Dr. H. Welzl for inspiring scientific discussions.

Bult, A., and Lynch, C. B. (1997). Nesting and fitness: lifetime reproductive success in house mice bidirectionally selected for thermoregulatory nest-building behavior. Behav. Genet. 27, 231-240. Castillo-Gómez, E., Gómez-Climent, M. A., Varea, E., Guirado, R., Blasco-Ibáñez, J. M., Crespo, C., Martínez-Guijarro, F. J., and Nácher, J. (2008). Dopamine acting through D2 receptors modulates the expression of PSA-NCAM, a molecule related to neuronal structural plasticity, in the medial prefrontal cortex of adult rats. Exp. Neurol. 214, 97-111.

Castillo-Gómez, E., Varea, E., BlascoIbáñez, J. M., Crespo, C., and Nacher, J. (2011). Polysialic Acid is required for dopamine D2 receptor-mediated plasticity involving inhibitory circuits of the rat medial prefrontal cortex. PLOS ONE 6:e29516. doi: 10.1371/journal.pone.0029516

Crawley, J. N. (2007). Mouse behavioral assays relevant to the symptoms of autism. Brain Pathol. 17, 448-459.

Cremer, H., Chazal, G., Goridis, C., and Represa, A. (1997). NCAM is essential for axonal growth and fasciculation in the hippocampus. Mol. Cell. Neurosci. 8, 323-335.
Cremer, H., Lange, R., Christoph, A., Plomann, M., Vopper, G., Roes, J., Brown, R., Baldwin, S., Kraemer, P., Scheff, S., Barthels, D., Rajewsky, K., and Wille, W. (1994). Inactivation of the N-CAM gene in mice results in size reduction of the olfactory bulb and deficits in spatial learning. Nature 367, 455-459.

DeLuca, J., Donovick, P. J., and Burright, R. G. (1989). Lead exposure, environmental temperature, nesting and consummatory behavior of adult male mice of two ages. Neurotoxicol. Teratol. 11, 7-11.

Delling, M., Wischmeyer, E., Dityatev, A., Sytnyk, V., Veh, R. W., Karschin, A., and Schachner, M. (2002). The neural cell adhesion molecule regulates cell-surface delivery of G-protein-activated inwardly rectifying potassium channels via lipid rafts. J. Neurosci. 22, 7154-7164.

Eckhardt, M., Bukalo, O., Chazal, G., Wang, L., Goridis, C., Schachner, M., Gerardy-Schahn, R., Cremer, H., and Dityatev, A. (2000). Mice deficient in the polysialyltransferase ST8SiaIV/PST-1 allow discrimination of the roles of neural cell adhesion molecule protein and polysialic acid in neural development and synaptic plasticity. J. Neurosci. 20, 5234-5244. 
Etherton, M. R., Blaiss, C. A., Powell, C. M., and Südhof, T. C. (2009). Mouse neurexin-1alpha deletion causes correlated electrophysiological and behavioral changes consistent with cognitive impairments. Proc. Natl. Acad. Sci. U.S.A. 106, 17998-18003.

Fields, R. D., and Itoh, K. (1996). Neural cell adhesion molecules in activity-dependent development and synaptic plasticity. Trends Neurosci. 19, 473-480.

Gainetdinov, R. R., Mohn, A. R., and Caron, M. G. (2001). Genetic animal models: focus on schizophrenia. Trends Neurosci. 24, 527-533.

Gejman, P. V., Sanders, A. R., and Kendler, K. S. (2011). Genetics of schizophrenia: new findings and challenges. Annu. Rev. Genomics Hum. Genet. 12, 121-144.

Gibbons, A. S., Thomas, E. A., and Dean, B. (2009). Regional and duration of illness differences in the alteration of NCAM-180 mRNA expression within the cortex of subjects with schizophrenia. Schizophr. Res. 112, 65-71.

Gray, L. J., Dean, B., Kronsbein, H. C., Robinson, P. J., and Scarr, E. (2010). Region and diagnosisspecific changes in synaptic proteins in schizophrenia and bipolar I disorder. Psychiatry Res. 178, 374-380.

Hildebrandt, H., Mühlenhoff, M., Oltmann-Norden, I., Röckle, I., Burkhardt, H., Weinhold, B., and Gerardy-Schahn, R. (2009). Imbalance of neural cell adhesion molecule and polysialyltransferase alleles causes defective brain connectivity. Brain 132, 2831-2838.

Hu, H., Tomasiewicz, H., Magnuson, T., and Rutishauser, U. (1996). The role of polysialic acid in migration of olfactory bulb interneuron precursors in the subventricular zone. Neuron 16, 735-743.

Isomura, R., Kitajima, K., and Sato, C. (2011). Structural and functional impairments of polysialic acid by a mutated polysialyltransferase found in schizophrenia. J. Biol. Chem. 286, 21535-21545.

Jaaro-Peled, H., Ayhan, Y., Pletnikov, M. V., and Sawa, A. (2010). Review of pathological hallmarks of schizophrenia: comparison of genetic models with patients and nongenetic models. Schizophr. Bull. $36,301-313$

Joober, R., Boksa, P., Benkelfat, C., and Rouleau, G. (2002). Genetics of schizophrenia: from animal models to clinical studies. J. Psychiatry Neurosci. 27, 336-347.

Kalueff, A. V., Keisala, T., Minasyan, A., Kuuslahti, M., Miettinen, S., and Tuohimaa, P. (2006). Behavioural anomalies in mice evoked by "Tokyo" disruption of the Vitamin D receptor gene. Neurosci. Res. 54, 254-260.

Kellendonk, C., Simpson, E. H., and Kandel, E. R. (2009). Modeling cognitive endophenotypes of schizophrenia in mice. Trends Neurosci. 32, 347-358.

Kochlamazashvili, G., Senkov, O., Grebenyuk, S., Robinson, C., Xiao, M. F., Stummeyer, K., GerardySchahn, R., Engel, A. K., Feig, L., Semyanov, A., Suppiramaniam, V., Schachner, M., and Dityatev, A. (2010). Neural cell adhesion molecule-associated polysialic acid regulates synaptic plasticity and learning by restraining the signaling through GluN2B-containing NMDA receptors. J. Neurosci. 30, 4171-4183.

Kolomeets, N. S., Orlovskaya, D. D., and Uranova, N. A. (2007). Decreased numerical density of CA3 hippocampal mossy fiber synapses in schizophrenia. Synapse 61, 615-621.

Laxmi, T. R., Stork, O., and Pape, H. C. (2003). Generalisation of conditioned fear and its behavioural expression in mice. Behav. Brain Res. $145,89-98$.

Lisman, J. (2011). Excitation, inhibition, local oscillations, or largescale loops: what causes the symptoms of schizophrenia? Curr. Opin. Neurobiol. [Epub ahead of print].

Lu, L., Mamiya, T., Koseki, T., Mouri, A., and Nabeshima, T. (2011). Genetic animal models of schizophrenia related with the hypothesis of abnormal neurodevelopment. Biol. Pharm. Bull. 34, 1358-1363.

Lubow, R. E. (2005). Construct validity of the animal latent inhibition model of selective attention deficits in schizophrenia. Schizophr. Bull. 31, 139-153.

Markram, K., Gerardy-Schahn, R., and Sandi, C. (2007). Selective learning and memory impairments in mice deficient for polysialylated NCAM in adulthood. Neuroscience 144, 788-796.

Mazzongini, R., Zoli, M., Tosato, S., Lasalvia, A., and Ruggeri, M. (2009). Can the role of genetic factors in schizophrenia be enlightened by studies of candidate gene mutant mice behaviour?
World, J. Biol. Psychiatry 10, 778-797.

Moretti, P., Bouwknecht, J. A., Teague, R., Paylor, R., and Zoghbi, H. Y. (2005). Abnormalities of social interactions and home-cage behavior in a mouse model of Rett syndrome. Hum. Mol. Genet. 14, 205-220.

O'Tuathaigh, C. M., Babovic, D. O’Meara, G., Clifford, J. J., Croke, D. T., and Waddington, J. L. (2007) Susceptibility genes for schizophrenia: characterisation of mutant mouse models at the level of phenotypic behaviour. Neurosci. Biobehav. Rev. 31, 60-78.

Pillai-Nair, N., Panicker, A. K., Rodriguiz, R. M., Gilmore, K. L., Demyanenko, G. P., Huang, J. Z., Wetsel, W. C., and Maness, P. F. (2005). Neural cell adhesion molecule-secreting transgenic mice display abnormalities in GABAergic interneurons and alterations in behavior. J. Neurosci. 25, 4659-4671.

Plappert, C. F., Schachner, M., and Pilz, P. K. (2005). Neural cell adhesion molecule-null mice are not deficient in prepulse inhibition of the startle response. Neuroreport 16 , 1009-1012.

Povlsen, G. K., and Ditlevsen, D. K. (2010). The Neural Cell Adhesion Molecule NCAM and Lipid Rafts. Adv. Exp. Med. Biol. 663, 183-198.

Robertson, G. S., Hori, S. E., and Powell, K. J. (2006). Schizophrenia: an integrative approach to modelling a complex disorder. J. Psychiatry Neurosci. 31, 157-167.

Ronn, L. C., Berezin, V., and Bock, E. (2000). The neural cell adhesion molecule in synaptic plasticity and ageing. Int. J. Dev. Neurosci. 18, 193-199.

Samaco, R. C., Fryer, J. D., Ren, J., Fyffe, S., Chao, H. T., Sun, Y., Greer, J. J., Zoghbi, H. Y., and Neul, J. L. (2008). A partial loss of function allele of methyl-CpG-binding protein 2 predicts a human neurodevelopmental syndrome. Hum. Mol. Genet. 17, 1718-1727.

Seki, T., and Rutishauser, U. (1998). Removal of polysialic acid-neural cell adhesion molecule induces aberrant mossy fiber innervation and ectopic synaptogenesis in the hippocampus. J. Neurosci. 18, 3757-3766.

Stork, O., Welzl, H., Cremer, H., and Schachner, M. (1997). Increased intermale aggression and neuroendocrine response in mice deficient for the neural cell adhesion molecule (NCAM). Eur. J. Neurosci. 9, 1117-1125.

Stork, O., Welzl, H., Wolfer, D., Schuster, T., Mantei, N., Stork, S., Hoyer, D., Lipp, H., Obata, K., and Schachner, M. (2000). Recovery of emotional behaviour in neural cell adhesion molecule (NCAM) null mutant mice through transgenic expression of NCAM180. Eur. J. Neurosci. 12, 3291-3306.

Stork, O., Welzl, H., Wotjak, C. T., Hoyer, D., Delling, M., Cremer, H., and Schachner, M. (1999). Anxiety and increased 5-HT1A receptor response in NCAM null mutant mice. J. Neurobiol. 40, 343-355.

Sullivan, P. F., Keefe, R. S., Lange, L. A., Lange, E. M., Stroup, T. S., Lieberman, J., and Maness, P. F. (2007). NCAM1 and neurocognition in schizophrenia. Biol. Psychiatry 61, 902-910.

Tamminga, C. A., Stan, A. D., and Wagner, A. D. (2010). The hippocampal formation in schizophrenia. Am. J. Psychiatry 167, 1178-1193.

Tao, R., Li, C., Zheng, Y., Qin, W., Zhang, J., Li, X., Xu, Y., Shi, Y. Y., Feng, G., and He, L. (2007). Positive association between SIAT8B and schizophrenia in the Chinese Han population. Schizophr. Res. 90, 108-114.

Terwisscha van Scheltinga, A. F., Bakker, S. C., and Kahn, R. S. (2010). Fibroblast growth factors in schizophrenia. Schizophr. Bull. 36, 1157-1166.

Tordjman, S., Drapier, D., Bonnot, O., Graignic, R., Fortes, S., Cohen, D., Millet, B., Laurent, C., and Roubertoux, P. L. (2007). Animal models relevant to schizophrenia and autism: validity and limitations. Behav. Genet. 37, 61-78.

Turetsky, B. I., Moberg, P. J., Yousem, D. M., Doty, R. L., Arnold, S. E., and Gur, R. E. (2000). Reduced olfactory bulb volume in patients with schizophrenia. Am. J. Psychiatry $157,828-830$

Uhlhaas, P. J., Haenschel, C., Nikoliæ, D., and Singer, W. (2008). The role of oscillations and synchrony in cortical networks and their putative relevance for the pathophysiology of schizophrenia. Schizophr. Bull. 34, 927-943.

Varea, E., Blasco-Ibáñez, J. M., GómezCliment, M. A., Castillo-Gómez, E., Crespo, C., Martínez-Guijarro, F. J., and Nácher, J. (2007). Chronic fluoxetine treatment increases the expression of PSA-NCAM in the medial prefrontal cortex. 
Neuropsychopharmacology

32, 803-812.

Vawter, M. P. (2000). Dysregulation of the neural cell adhesion molecule and neuropsychiatric disorders. Eur. J. Pharmacol. 405, 385-395.

Vawter, M. P., Usen, N., Thatcher, L., Ladenheim, B., Zhang, P., VanderPutten, D. M., Conant, K., Herman, M. M., van Kammen, D. P., Sedvall, G., Garver, D. L., and Freed, W. J. (2001). Characterization of human cleaved N-CAM and association with schizophrenia. Exp. Neurol. 172, 29-46.

Vicente, A. M., Macciardi, F., Verga, M., Bassett, A. S., Honer, W. G., Bean, G., and Kennedy, J. L.
(1997). NCAM and schizophrenia: genetic studies. Mol. Psychiatry 2, 65-69.

Walker, E., Mittal, V., and Tessner, K. (2008). Stress and the hypothalamic pituitary adrenal axis in the developmental course of schizophrenia. Annu. Rev. Clin. Psychol. 4, 189-216. Review.

Weiner, I. (2003). The "two-headed" latent inhibition model of schizophrenia: modeling positive and negative symptoms and their treatment. Psychopharmacology (Berl.) 169, 257-297.

Xiao, M. F., Xu, J. C., Tereshchenko, Y., Novak, D., Schachner, M., and Kleene, R. (2009). Neural cell adhesion molecule modulates dopaminergic signaling and behavior by regulating dopamine D2 receptor internalization. J. Neurosci. 29, 14752-14763.

Yamada, K., Iwayama, Y., Toyota, T., Ohnishi, T., Ohba, H., Maekawa, M., and Yoshikawa, T. (2012). Association study of the KCNJ3 gene as a susceptibility candidate for schizophrenia in the Chinese population. Hum. Genet. 131, 443-451.

Conflict of Interest Statement: The authors declare that the research was conducted in the absence of any commercial or financial relationships that could be construed as a potential conflict of interest.

Received: 23 May 2012; accepted: 30 June 2012; published online: 17 July 2012.

Citation: Albrecht A and Stork O (2012) Are NCAM deficient mice an animal model for schizophrenia? Front. Behav. Neurosci. 6:43. doi: 10.3389/ fnbeh.2012.00043

Copyright () 2012 Albrecht and Stork. This is an open-access article distributed under the terms of the Creative Commons Attribution License, which permits use, distribution and reproduction in other forums, provided the original authors and source are credited and subject to any copyright notices concerning any third-party graphics etc. 